\title{
BONE HEIGHT CHANGES AROUND IMMEDIATELY LOADED IMPLANT-RETAINED MANDIBULAR OVER DENTURES WITH TWO DIFFERENT OCCLUSAL SCHEMES
}

\author{
Hossam I Nassar* and Mai Adel Helmy**
}

\begin{abstract}
Purpose: To compare and evaluate the effect of two different occlusal schemes (lingualized and monoplane occlusion) on the bone height changes in immediate loaded implant-retained Mandibular overdenture with locator attachment

Materials and Methods: Twenty completely edentulous patients received two dental implants inserted in the Mandibular cuspids regions retaining an overdenture using locator attachment and they were divided into two equal groups. Group I were received overdenture with monoplane occlusal design, and Group II patients were received overdenture with lingualized occlusal design. Marginal bone height around implants was evaluated using Cone Beam Computed Tomography (CBCT) after 1 week, 6 months and 12 months of overdenture delivery.
\end{abstract}

Results: There was no statistically significant difference recorded between lingualized and monoplane occlusal scheme in implants retaining a Mandibular overdentures using locator attachment.

KEYWORDS: Dental Implant; Lingualized Occlusion, Monoplane Occlusion, locator Attachment, Overdenture.

\section{INTRODUCTION}

Mandibular denture usually possesses greater clinical problems related to support and retention for both the patient and the prosthodontist. The amount of bone reduction is greater in the mandible than in maxilla resulting in a reduction of denture supporting structure area with high muscular attachment. ${ }^{(1)}$
The use of osseointegrated dental implants placed in between two mental foramina, in implantretained overdentures, dramatically improve the stability, retention and biting force of completely edentulous patients with a subsequent increase in satisfaction and comfort with their dentures. ${ }^{(2,3)}$ Several studies ${ }^{(4-6)}$ also document that the use of two implants can lead to a decrease in the pattern of alveolar bone Resorption rate.

\footnotetext{
* Associated Professor of Removable Prosthodontics Department, Faculty of Dentistry, Future University in Egypt.

** Lecture of Removable Prosthodontics Department, Faculty of Dentistry, Cairo University.
} 
Different concepts and schools were suggested in complete denture occlusal schemes to maximize the stability, esthetic and masticatory efficiency without compromising the health of underlying hard and soft tissues of the edentulous arch.

The aims of those philosophies were to minimize lateral forces applied to an inclined occlusal surface. ${ }^{(7,8)}$

Selection of posterior tooth forms for implant retained overdentures is presently made according to personal partiality and understanding by using concepts of conventional complete dentures occlusion., Many studies (9-11) recommended that selection of cusped teeth with an attention that it should be in a complete harmony with the stomatognathic system.

However, other studies ${ }^{(12,13)}$ recommended the use of zero degree teeth proposing that cuspless teeth could create the minimum horizontal force on denture supporting structures.

The principle of lingualized occlusion was introduced as an challenge to maintain the advantage of the anatomic form regarding esthetics and functional efficiency in addition to maintain the mechanical freedom of non-anatomic form. In this principle, only the upper palatal cusps occlude with Mandibular central fossae improving the comfort, function, and appearance of the patient. ${ }^{(7,13)}$

In this study, the effect of using two different occlusal schemes, median lingualized occlusion, and monoplane occlusion, on bone height changes around immediate loaded implant-retained Mandibular overdenture with locator attachment will be studied.

\section{MATERIAL AND METHODS}

The study was carried out in the Department of Removable Prosthodontics, Faculty of Oral and Dental Medicine, Future University and Cairo University. The population of this study constituted of 20 male patients who have been treated with implant retained Mandibular overdentures using locator attachment. Using a table of random numbers, the participants were randomly assigned to two equal groups. Group I were received overdenture with an artificial teeth arranged in a monoplane occlusion design, and Group II were patients received overdenture with artificial teeth arranged in lingualized occlusion design. All patients completed a follow-up period of one year without any dropout.

The patients age ranged between 42 and 60 years. The fundamental inclusion criteria were edentulous patients in need of an overdenture with adequate inter-arch space and in whom at least one implant could be placed bilaterally. Patients with bruxism, history of bone grafting procedures, uncontrolled systemic diseases . smokers and irradiated cancer patients were excluded. The implants installed were measured for initial stability using Osstell Mentor (Osstell AB, Göteborg, Sweden)and those measured below 60 Implant stability quotient (ISQ) values were not immediately loaded and excluded from this study. The patients approved with written informed consent. The study was conducted in accordance with the Helsinki Declaration of 1975 for medical studies, as revised in 2000 and the study has been independently reviewed and approved by an ethics committee review board at Future University. Patient selection was based on clinical and radiographic examinations using cone beam computed tomography.

\section{Prosthetic procedures}

Preliminary impressions with irreversible hydrocolloids impression material were done. Secondary impressions were taken with a custommade tray using polyether material (Impregum F, ESPE). Standardization of laboratory procedures was accomplished with one dental technician. Centric relation records were performed by an unstrained guided method, and the bite registration 
were transferred to semi-adjustable articulators (Amann Girrbach AG Herrschaftswiesen 16842 Koblach Austria) by means of a facebow. After jaw relation record the setting of artificial teeth was done in the following manner:

For group I patients the monoplane occlusion was done. Flat Mesio -distally and buccolingually teeth (Zero degree posterior teeth) were used. The upper and lower anterior teeth were arranged with no vertical overlap =zero overlap. The occlusal plane should bisect the inter-arch space evenly and the mean foundation plane should be parallel to each other and ended at the junction not exceed two - third of the retromolar pad .

For group II patients the lingualized occlusion was done. For esthetic and phonetic demands the anterior teeth were arranged with adequate vertical overlap and with sufficient horizontal overlap in order to avoid interference during protrusive and lateral movements. The maxillary posterior Buccal cusps were reduced $1 \mathrm{~mm}$ in order to eliminate the Buccal contact in both centric and eccentric jaw relations. The palatal cusps of the upper posterior teeth were arranged to articulate with the modified central fossae of the lower posterior teeth in centric working and non-working Mandibular position. fig. (1)
High-impact denture base acrylic resin (Lucitone, Dentsply) were used. No dentures were reinforced with a cast cobalt-chromium framework. Selective grinding procedures were followed, and the occlusion was refined intraorally using articulating paper. All dentures were designed to obtain optimal support from denture base coverage of the supporting mucosa, which was revealed on insertion by pressure-indicating paste.

\section{Implant Installation}

The surgical procedures were performed using Implant Direct (Spectra-system and Legacy) dental implants. The implant lengths were $13 \mathrm{~mm}$. The selection of implant length was dictated by the preoperative cone beam radiographic measurement of bone height and width in the canine region and drilling distance, with the main concern of achieving primary stability. A total of 42 dental implants were placed. The implants were inserted under local anesthesia in one stage procedure. The implants were installed for initial torque above 30 $\mathrm{N} \mathrm{cm}$ to ensure initial stability and those measured below were not immediately loaded and excluded from this study. The implant retained prosthesis was applied immediately after the placement of the implants using locator attachment. fig.(2)

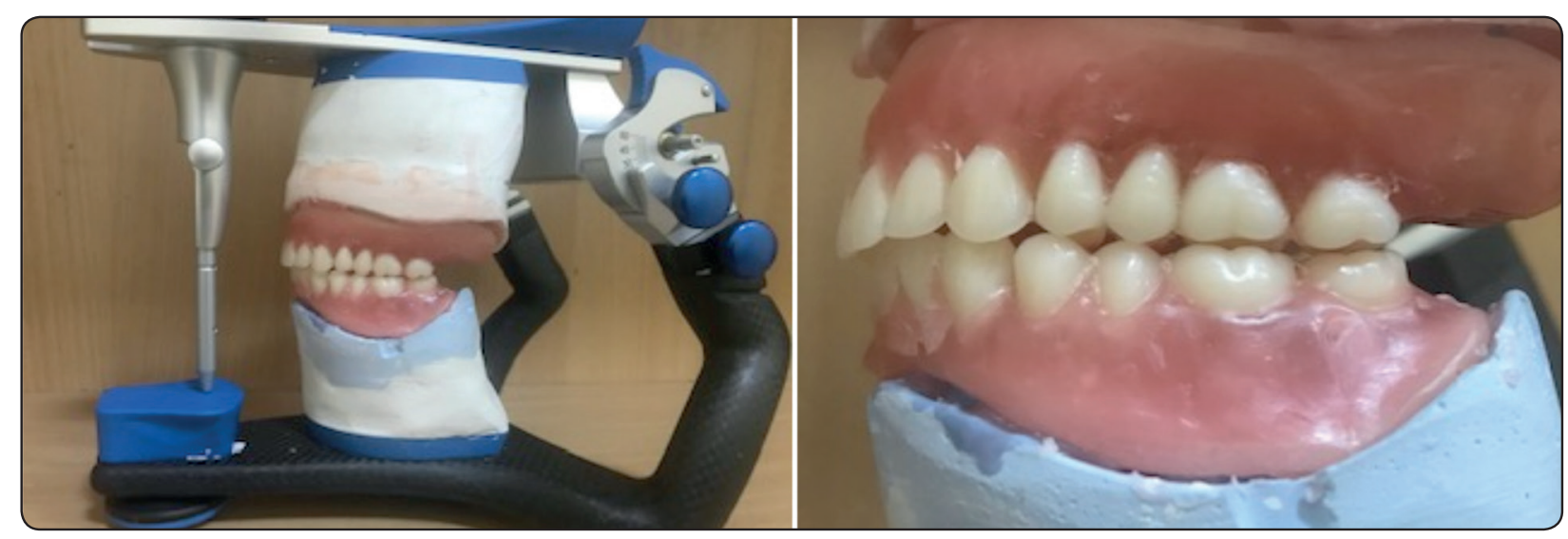

Fig. (1) setting up the posterior teeth in lingualized occlusion manner. 


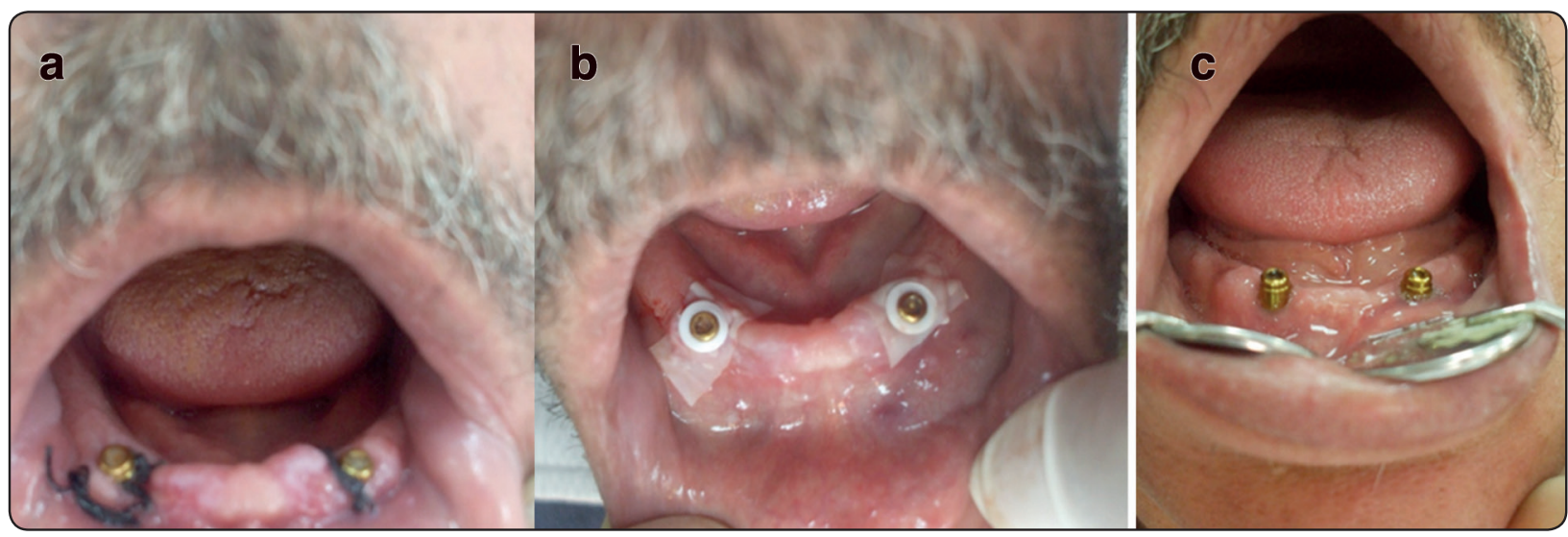

Fig. (2) : a. suturing around the locators , b. White block out spacer and a rubber dam were slipped around the locators, c. Complete healing of soft tissue surrounding the locators.

The areas opposing to the locators were marked on the fitting surface of the Mandibular complete denture. The fitting surface of the denture was relieved hollowed directly above the implants and create enough space was made to accommodate the locators. A small hole was prepared at the lingual flange to allow for escape of excess cold curing polymerizing resin during direct picking up. The denture was removed, trimmed and polished with the metal housings picked up in its fitting surface.

The patients were asked to rinse with $0.12 \%$ chlorhexidine mouthwash three times daily for 14 days and not to remove the denture during mastication for one week, without brushing off the operated areas. Sutures were removed two weeks thereafter.

\section{Radiographic follow-up}

Dental Cone Beam Computed Tomography (CBCT) was used for radiographic assessment. The machine was adjusted so that the slice thicknesses of the axial cuts were $0.625 \mathrm{~mm}$; the bony window was chosen and zero gantry tilt. The axial cuts were only performed on the mandible to reduce the radiation dose. All patients performed three CBCT scans. The baseline scan was performed one week after the surgery. The next scans were performed six and twelve months from the date of surgery. After obtaining the images a computer software program to assess bone height changes around implants were used, whereby coronal and sagittal reformatting was done.

\section{Statistical analysis}

Data analysis was performed with (ANOVA) and t-test as a function of follow up period. the software using is GraphPad Prism-4 statistics for Windows. $\mathrm{P}$ values less than 0.05 are considered to be statistically significant in all tests.

\section{RESULTS}

The mean bone changes after six and twelve months in group one patients with median lingualized occlusion were $(0.59 \mathrm{~mm}$ and $0.93 \mathrm{~mm})$. The mean bone changes after six and twelve months in group two patients with monoplane occlusion were (0.59 $\mathrm{mm}$ and $0.97 \mathrm{~mm})$. No statistically significant difference was recorded between two groups after six and twelve months follow up. (Table1) 
TABLE (1) Bone height changes of lingualized occlusion and monoplane occlusion groups at the different intervals of the follow-up period.

\begin{tabular}{|l|c|c|c|c|c|c|}
\hline \multirow{2}{*}{ Group } & \multicolumn{2}{|c|}{ 1 WEEK } & \multicolumn{2}{c|}{ 6 MONTHS } & \multicolumn{2}{c|}{ 12 MONTHS } \\
\cline { 2 - 7 } & Mean & SD & Mean & SD & Mean & SD \\
\hline lingualized occlusion (MLO) & 12.82 & 0.071 & 12.23 & 0.131 & 11.99 & 0.13 \\
\hline Monoplane occlusion (MPO) & 12.86 & 0.12 & 12.27 & 0.12 & 11.88 & 0.11 \\
\hline P value & \multicolumn{2}{|c|}{0.54} & \multicolumn{2}{|c|}{0.62} & \multicolumn{2}{c|}{0.34} \\
\hline
\end{tabular}

\section{DISCUSSION}

The patients in the present study were rehabilitated with two immediately loaded Mandibular implants to retain an overdenture. The major advantages for immediate loading protocol include decreasing surgical procedures, earlier rehabilitation, and improving patient comfort and satisfaction. ${ }^{(14,15)}$

All selected patients had a normal ridge relationship with enough inter-ridge space to allow for placing the denture over the implant abutments without increasing the vertical dimension of occlusion. ${ }^{(16)}$ To exclude the negative influence of hormonal changes on the oral mucosa and bone, male patients were preferred over female ones. ${ }^{(17)}$ poor oral hygiene was reported as one of the important causes of osseointegration failure; hence all the patients were educated and motivated for regular and strict oral, implants and overdenture hygiene. Also, the smokers were excluded as these patients may show generalized bone loss to the implants this fact may attributable to the compromised blood supply to the bone during healing. ${ }^{(18)}$

The implant survival rate for the forty placed dental implant was $100 \%$. High implant survival rate was reported early in literature. Schnitman et. al, ${ }^{(19)}$ reported an $84.7 \%$ survival rate of 28 immediately loaded implants during ten years to follow up. SanzSanchez et. al ${ }^{(20)}$ documented a systematic review and meta-analysis showing that immediate loading protocols might impress a higher risk for implant failure when compared to conventional ones, although both groups showed high survival rates.

However, other studies reported significantly lower survival rates when compared to conventional loading. Ottoni and coworkers ${ }^{(21)}$, reported oneyear survival rate of $56.53 \%$ for immediately loaded implants, in comparison with a $95.66 \%$ survival rate with conventional loading in 23 patients. Taking into consideration that, nine implants that failed out the ten immediately loaded implants had low implant primary stability below $20 \mathrm{Ncm}$ torque. The authors in the later study agreed that a minimum primary stability should be an obligation for immediately loaded implants. All implants in the present study were measured for initial stability and those measured below $30 \mathrm{Ncm}$ torque were not immediately loaded and excluded from this study.

The occlusal scheme of the complete denture is one of the factors that affects the masticatory efficiency and chewing pattern of the patients. (22) The intensity and the quantity of contacts with dentures conclude the amount and the direction of the forces that are transmitted to the residual ridges through the denture bases. That describe why the occlusal scheme is considered an important factor in the design of complete dentures. ${ }^{(8,23)}$ 
The present study was the earliest to estimate marginal bone changes in immediately loaded implants retaining a Mandibular overdenture with Locator attachments utilizing different occlusal scheme, logically it was difficult to compare directly our results with other studies.

The mean marginal bone changes were ( 0.93 $\mathrm{mm}$ and $0.97 \mathrm{~mm}$ ) respectively with no statistically significant difference between the two groups. This bone loss value of $1 \mathrm{~mm}$ after the first year around implants remains in the usual range documented in many kinds of literature. ${ }^{24,25)}$ The changes in bone height with the progress of time may be due to the immediate bone response to osseointegration and healing joint with function and masticatory forces. (26)

The masticatory forces increase the magnitude of the bending moment acting on two solitary implants retaining an overdenture. (27) The consequent implant micromovement has an unfavorable effect on the implant to bone interface leading to the larger bone turnover and impair primary healing around implants. ${ }^{(28,29)}$

Similar results were recorded in other studies. M.A. Elsayed et. al, ${ }^{(30,31)}$ compared crestal bone loss and clinical outcomes between two different loading protocols (immediate and delayed) supporting Mandibular overdentures in two different studies. They concluded that immediately loaded implants were associated with a more crestal bone loss when compared to delayed ones although, clinical outcomes did not show statistically significant difference between loading protocols. In the first study, ball attachment was used and the mean bone changes for an immediately loaded group were 0.91 $\mathrm{mm}$ after one year and $0.98 \mathrm{~mm}$ after 3 years follow up period. While in the second study the mean bone changes for an immediately loaded group were $1.05 \mathrm{~mm}$ after one year follow up period utilizing Locator attachment. Liao et al. ${ }^{(32)}$ reported 1.12 $\mathrm{mm}$ crestal bone loss subsequent to the immediate loading of two unsplinted implants with Mandibular overdentures after one year.

On the other hand, other studies ${ }^{(33-35)}$ documented lower crestal bone loss rates of $0.3 \mathrm{~mm}$ and 0.6 $\mathrm{mm}$ during the first year of implant loading. The authors attributed the lower marginal bone loss rates to the reduced micro movement transmitted to immediately loaded implants. Several factors such as implant primary stability with initial torque installation above $40 \mathrm{Ncm}$, the roughness of implant surface, denture stability and the control of the occlusal forces served in reducing micromotion in the early healing period.

\section{CONCLUSION}

Different occlusal schemes seem to have minimal influence on bone height changes around immediately loaded implant-retained Mandibular overdentures in short-term follow up of one year.

\section{REFERENCES}

1. Douglass JB, Meader L, Kaplan A, Ellinger CW. Cephalometric evaluation of the changes in patients wearing complete dentures: a 20-year study. J Prosthet Dent. 1993;69(3):270-5.

2. Walton JN, Glick N, Macentee MI. A randomized clinical trial comparing patient satisfaction and prosthetic outcomes with mandibular overdentures retained by one or two implants. J Prosthet Dent . 2009 Jul-Aug;22(4):331-9.

3. Kuoppala R, Näpänkangas R, Raustia A. Quality of life of patients treated with implant-supported mandibular overdentures evaluated with the Oral Health Impact Profile (OHIP-14): a survey of 58 patients. J Oral Maxillofac Surg 2013;4(2).

4. Boven G, Raghoebar G, Vissink A, Meijer H. Improving masticatory performance, bite force, nutritional state and patient's satisfaction with implant overdentures: a systematic review of the literature. J Oral Rehabil. 2015; 42(3):220-33.

5. Thomason J, Kelly S, Bendkowski A, Ellis J. Two implant retained overdentures-A review of the literature supporting the McGill and York consensus statements. Journal of dentistry. 2012;40(1):22-34. 
6. Shastry T, Anupama N, Shetty S, Nalinakshamma M. An in vitro comparative study to evaluate the retention of different attachment systems used in implant-retained overdentures. J Indian Prosthodont Soc. 2016;16(2):159.

7. Phoenix RD, Engelmeier RL. Lingualized occlusion revisited. J Prosthet Dent. 2010;104(5):342-6.

8. Tarazi E, Ticotsky-Zadok N. Occlusal schemes of complete dentures--a review of the literature. Refu'at ha-peh vehashinayim (1993). 2007;24(1):56-64, 85-6.

9. Matsumaru Y. Influence of mandibular residual ridge resorption on objective masticatory measures of lingualized and fully bilateral balanced denture articulation. J Prosthodont Res. 2010;54(3):112-8.

10. Zhao K, Mai Q-Q, Wang X-D, Yang W, Zhao L. Occlusal designs on masticatory ability and patient satisfaction with complete denture: a systematic review. Journal of dentistry. 2013;41(11):1036-42.

11. Jaafar Abduo B, DclinDent M. Occlusal schemes for complete dentures: a systematic review. Int J Prosthodont. 2013;26:26-33.

12. Mankani N, Chowdhary R, Mahoorkar S. Comparison of stress dissipation pattern underneath complete denture with various posterior teeth form: an in vitro study. The J Indian Prosthodont Soc. 2013;13(3):212-9.

13. Prasad KD, Prasad BR, Bardia A, Prasad AD. Enhancing stability: A review of various occlusal schemes in complete denture prosthesis. Nitte University Journal of Health Science. 2013;3(2):105.

14. Kronstrom M, Davis B, Loney R, Gerrow J, Hollender L. A prospective randomized study on the immediate loading of mandibular overdentures supported by one or two implants: a 12-month follow-up report. Int J Oral Maxillofac Implants. 2010 Jan-Feb;25(1):181-8.

15. Goiato MC, Bannwart LC, Pesqueira AA, Dos Santos DM, Haddad MF, Santos MR, et al. Immediate loading of overdentures: systematic review. J Oral Maxillofac Surg. 2014;18(3):259-64.

16. Todescan S, Lavigne S, Kelekis-Cholakis A. Guidance for the maintenance care of dental implants: clinical review. J Can Dent Assoc. 2012;78(1):107.

17. Friedlander AH. The physiology, medical management and oral implications of menopause. J Am Dent Assoc. 2002;133(1):73-81.
18. Tecco S, Grusovin M, Sciara S, Bova F, Pantaleo G, Capparé $\mathrm{P}$. The association between three attitude-related indexes of oral hygiene and secondary implant failures: A retrospective longitudinal study. INT J DENT HYG. 2018;16(3):372-9.

19. Schnitman PA, Wöhrle PS, Rubenstein JE, DaSilva JD, Wang N-H. Ten-year results for Brånemark implants immediately loaded with fixed prostheses at implant placement. Int J Oral Max Impl. 1997;12(4).

20. Sanz-Sánchez I, Sanz-Martín I, Figuero E, Sanz M. Clinical efficacy of immediate implant loading protocols compared to conventional loading depending on the type of the restoration: a systematic review. Clin Oral Implants Res. 2015;26(8):964-82.

21. Ottoni JMP, Oliveira ZFL, Mansini R, Cabral AM. Correlation between placement torque and survival of single-tooth implants. Int J Oral Max Impl. 2005;20(5).

22. Miyashita K, Sekita T, Minakuchi S, Hirano Y, Kobayashi K, Nagao M. Denture mobility with six degrees of freedom during function. J Oral Rehabil. 1998;25(7):545-52.

23. Ahmed AR, Muneer MU, Hakeem S. Masticatory Efficiency Between Balanced and Lingualized Occlusion in Complete Denture Wearers. Pakistan Oral \& Dental Journal. 2013;33(1).

24. Roos J, Sennerby L, Lekholm U, Jemt T, Gröndahl K, Albrektsson T. A qualitative and quantitative method for evaluating implant success: a 5-year retrospective analysis of the Brånemark implant. Int J Oral Max Impl. 1997;12(4).

25. Albrektsson T, Zarb GA. Current interpretations of the osseointegrated response: clinical significance. Int $\mathrm{J}$ Prosthodont. 1993;6(2).

26. Hohlweg-Majert B, Metzger M, Kummer T, Schulze D. Morphometric analysis-cone beam computed tomography to predict bone quality and quantity. Journal of CranioMaxillofacial Surgery. 2011;39(5):330-4.

27. Heckmann SM, Wichmann MG, Winter W, Meyer M, Weber HP. Overdenture attachment selection and the loading of implant and denture-bearing area. Part 2: A methodical study using five types of attachment. Clin Oral Implants Res. 2001;12(6):640-7.

28. Alfadda SA, Attard NJ, David LA. Five-year clinical results of immediately loaded dental implants using mandibular overdentures. . Int J Prosthodont. 2009;22(4).

29. Akca K, Akkocaoğlu M, Cömert A, Tekdemir I, Cehreli MC. Bone strains around immediately loaded implants 
supporting mandibular overdentures in human cadavers. Int J Oral Max Impl. 2007;22(1).

30. Elsyad MA, Al-Mahdy YF, Fouad MM. Marginal bone loss adjacent to conventional and immediate loaded two implants supporting a ball-retained mandibular overdenture: a 3-year randomized clinical trial. Clin Oral Implants Res. 2012;23(4):496-503.

31. Elsyad M, Elsaih E, Khairallah A. Marginal bone resorption around immediate and delayed loaded implants supporting a locator-retained mandibular overdenture. A 1-year randomised controlled trial. J Oral Rehabil. 2014;41(8):608-18.

32. Liao K-Y, Kan JY, Rungcharassaeng K, Lozada JL, Herford AS, Goodacre CJ. Immediate loading of two freestanding implants retaining a mandibular overdenture: 1-year pilot prospective study. Int J Oral Max Impl. 2010;25(4).

33. Stricker A, Gutwald R, Schmelzeisen R, Gellrich NG. Immediate loading of 2 interforaminal dental implants supporting an overdenture: clinical and radiographic results after 24 months. Int J Oral Max Impl. 2004;19(6).

34. Turkyilmaz I, Tumer C, Avci M, Hersek N, Celik-Bagci E. A short-term clinical trial on selected outcomes for immediately loaded implant-supported mandibular overdentures. Int J Prosthodont. 2006;19(5).

35. Marzola R, Scotti R, Fazi G, Schincaglia GP. Immediate loading of two implants supporting a ball attachmentretained mandibular overdenture: a prospective clinical study. Clin Implant Dent Relat Res. 2007;9(3):136-43. 